This item was submitted to Loughborough's Research Repository by the author.

Items in Figshare are protected by copyright, with all rights reserved, unless otherwise indicated.

\title{
Local ventilation and wear response of working jackets with different fabric permeability
}

PLEASE CITE THE PUBLISHED VERSION

http://dx.doi.org/10.1108/IJCST-08-2014-0100

\section{PUBLISHER}

(C) Emerald Publishing

\section{VERSION}

AM (Accepted Manuscript)

\section{PUBLISHER STATEMENT}

This work is made available according to the conditions of the Creative Commons Attribution-NonCommercialNoDerivatives 4.0 International (CC BY-NC-ND 4.0) licence. Full details of this licence are available at: https://creativecommons.org/licenses/by-nc-nd/4.0/

\section{LICENCE}

CC BY-NC-ND 4.0

\section{REPOSITORY RECORD}

Ke, Ying, Jun Li, and George Havenith. 2019. "Local Ventilation and Wear Response of Working Jackets with Different Fabric Permeability”. figshare. https://hdl.handle.net/2134/19445. 


\section{Emerald Insight}

\section{International Journal of Clothing Science and Technology}

Local ventilation and wear response of working jackets with different fabric permeability

Ying Ke Jun Li George Havenith

\section{Article information:}

To cite this document:

Ying Ke Jun Li George Havenith , (2015),"Local ventilation and wear response of working jackets with different fabric permeability", International Journal of Clothing Science and Technology, Vol. 27 Iss 6 pp. -

Permanent link to this document:

http://dx.doi.org/10.1108/IJCST-08-2014-0100

Downloaded on: 12 October 2015, At: 03:35 (PT)

References: this document contains references to 0 other documents.

To copy this document: permissions@emeraldinsight.com

The fulltext of this document has been downloaded 4 times since 2015*

\section{Users who downloaded this article also downloaded:}

Kerry Fairbrother, James Warn, (2003),"Workplace dimensions, stress and job satisfaction", Journal of Managerial Psychology, Vol. 18 Iss 1 pp. 8-21 http://dx.doi.org/10.1108/02683940310459565

Syamsul Herman bin Mohammad Afandi, Zaiton Samdin, Ahmad bin Shuib, (2013),"Review of valuation from a non-market perspective: travel cost method for rural tourism", Worldwide Hospitality and Tourism Themes, Vol. 5 Iss 4 pp. 329-341 http:// dx.doi.org/10.1108/WHATT-03-2013-0018

Elaine Garcia, Ibrahim Elbeltagi, Martial Bugliolo, (2015),"Introducing 4G mobile networks: implications for UK higher education", International Journal of Information and Learning Technology, Vol. 32 Iss 2 pp. 124-135 http://dx.doi.org/10.1108/ IJILT-01-2015-0001

Access to this document was granted through an Emerald subscription provided by emerald-srm: 327770 []

\section{For Authors}

If you would like to write for this, or any other Emerald publication, then please use our Emerald for Authors service information about how to choose which publication to write for and submission guidelines are available for all. Please visit www. emeraldinsight. com/ authors for more information.

\section{About Emerald www.emeraldinsight.com}

Emerald is a global publisher linking research and practice to the benefit of society. The company manages a portfolio of more than 290 journals and over 2,350 books and book series volumes, as well as providing an extensive range of online products and additional customer resources and services.

Emerald is both COUNTER 4 and TRANSFER compliant. The organization is a partner of the Committee on Publication Ethics (COPE) and also works with Portico and the LOCKSS initiative for digital archive preservation. 


\section{Local ventilation and wear response of working jackets with different fabric permeability}

\section{Introduction}

Clothing microclimate ventilation (MV) is an important factor affecting human thermal comfort, especially in indoors environments (Havenith et al., 2010). Recently, more and more researches focused on the clothing local microclimate ventilation (LMV), for the regional differences in clothing microclimate volume, garment apertures design etc. (Ueda et al., 2006; Satsumoto and Havenith, 2010; Ke et al., 2013; Ke et al., 2014; Ke et al., 2014).

Normally, air exchange of clothing local microclimate has three pathways (Bouskill et al., 2002; Ke et al., 2013; Ke et al., 2014; Ke et al., 2014). First, it can directly exchange with the environmental air through garment fabric and therefore the fabric permeability should be in consideration. Second, the air exchange can also be conducted through garment openings by natural or forced convection (Bogerd et al., 2012). Third, air exchange among garment parts is also effective. While, only the first two pathways help the heat and moisture transfer through clothing, and then affecting the clothing thermal-wet properties and wear responses. Ke et al. studied on the relationship between clothing local ventilation and the thermal regional thermal insulation. Unfortunately, no significant correlation result was found (Ke et al., 2014). And how much effective ventilation occurs under clothing local microclimate and how the ventilation affects wearer response have so far received limited attention.

Two methods for measuring clothing ventilation have already been developed and used widely, which were developed by Crockford (CR) and Lotens with Havenith (LH), separately (Birnbaum and Crockford, 1978; Lotens and Havenith, 1988; Havenith et al., 1990). CR method was more complicated compared with LH's, as it needed to measure the microclimate volume. And based on these basic methods, different devices as well as their setups for measuring ventilation of clothing, diapers, shoes and so on were designed and built (Lotens and Havenith, 1988; Holland et al., 1999; Ueda et al., 2006; Satsumoto et al., 2008; Satsumoto and Havenith, 2010; Satsumoto et al., 2011). Meanwhile, system was also developed to measure the local ventilation at different garment parts, simultaneously or separately (Ke et al., 2014; Ke et al., 2014).

Clothing ventilation has gradually been considered when researchers studied the effects of clothing on the heat balance between human and the environment. Bouskill et al. indicated that thermal insulation had linear correlation with clothing ventilation (Bouskill et al., 2002). But they focused on the whole garment. Ueda et al. investigated the effects of clothing ventilation of three garment regions on the humidity of local clothing microclimate in light exercise. They proved that the ratio of the mean moisture concentration in the clothing microclimate to the mean sweat rate at the cheat and back correlated with clothing local ventilation (Ueda et al., 2006). However, neither of the above studies considered the possible relationships between clothing local ventilation and wear response.

The purpose of this study was to investigate the local ventilation of three garment regions: the right arm, the chest, the back and wear responses of three working jackets with different fabric permeability. In addition, the relationships between the local ventilation and the related wearer responses were also discussed. The LMV of the three garment regions were measured using the setup built based on the LH's method. The local skin temperature, microclimate temperature and 
humidity, clothing surface temperature, heart rate, eardrum temperature and subjective perceptions (thermal sensation, wetness sensation, comfort sensation) of the experimental garments were tested and recorded.

\section{Methods}

\subsection{Clothing local ventilation measuring system}

A clothing local ventilation measuring system was developed based on the steady state method (Lotens and Havenith, 1988; Ke et al., 2014; Ke et al., 2014). Therefore it is no need to measure the local microclimate volume. $\mathrm{N}_{2}$ was chosen as the tracer gas. Figure 1 presented the photos of the setup. The system has two improvements compared to LH's. First, it can measure the LMV of four body parts--the chest, the back, the right arm and the left arm simultaneously or separately. And the clothing whole ventilation can also be computed indirectly. Second, four tracer gas analyzers were adopted to decrease the testing time. The LMV was computed according to equation (1). Details about the system can also be found in the previous studies (Ke et al., 2014; Ke et al., 2014).

Vent $_{i}=\mathrm{FR}_{i} \times \frac{C_{\text {in }, i}-C_{\text {out }, i}}{C_{\text {out }, i}-C_{\text {air }, i}}$

Where i stands for the different garment regions, from 1 to 4; FR is the flow rate of the local circulating system (L/min); $C_{\text {in }}$ is the $N_{2}$ concentration of the inlet flow (\%); $C_{\text {out }}$ is the $N_{2}$ concentration of the outlet flow, that is the $\mathrm{N}_{2}$ concentration under the local microclimate (\%); $C_{\text {air, }}$ is the $N_{2}$ concentration of the air around the $i_{\text {th }}$ clothed body (\%) (Ke et al., 2014).

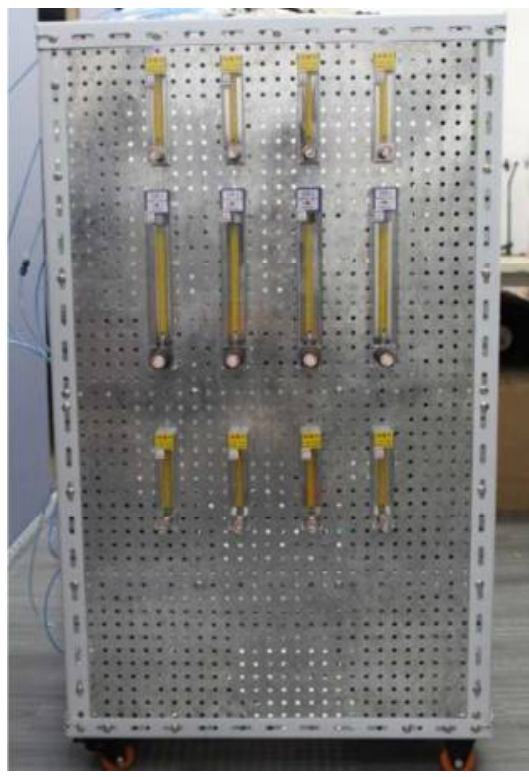

(a)

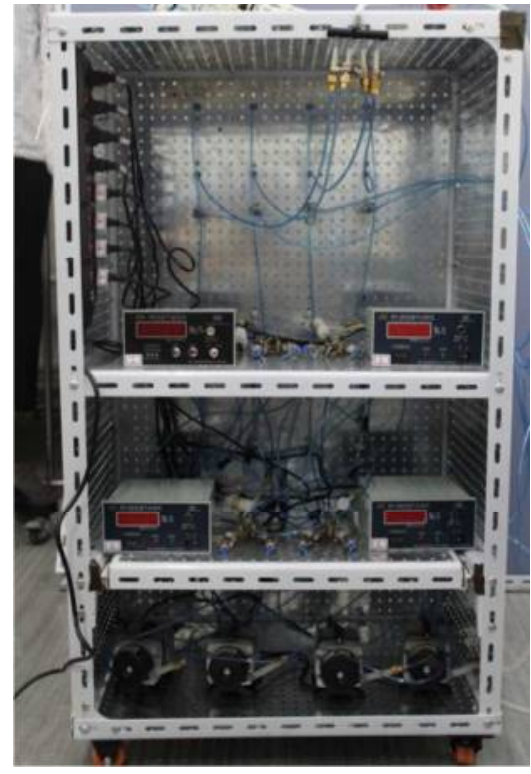

(b)

Figure 1. Clothing local ventilation measuring system. (a) front side; (b) back side (Ke et al., 2014).

\subsection{Participants}

A total of 5 healthy male university students (age $23.2 \pm 1.9$ years, height $175.1 \pm 2.9 \mathrm{~cm}$, weight 
$65.9 \pm 2.9 \mathrm{~kg}$ ) volunteered in this study. And the average Chest, waist, and hip circumference of the subjects were $88.5 \pm 3.9,75.5 \pm 3.7$ and $93.2 \pm 4.0 \mathrm{~cm}$. All participants were fully informed of all the procedures and protocols before signing a statement of informed consent.

\subsection{Fabrics and garments}

Three different fabrics with the same thickness $(0.48 \mathrm{~mm})$ and structure (twill) were chosen. The biggest difference of these fabrics was the air permeability. And the fabrics were named according to it: PM--permeable, SM--semi-permeable, IM--impermeable. Table 1 showed the basic measurements of the experimental fabrics. PM and SM were $100 \%$ cotton fabrics. The IM fabric was made by the SM fabric laminated with an impermeable thin coating.

Table 1

Specifications of the experimental fabrics (Ke et al., 2014).

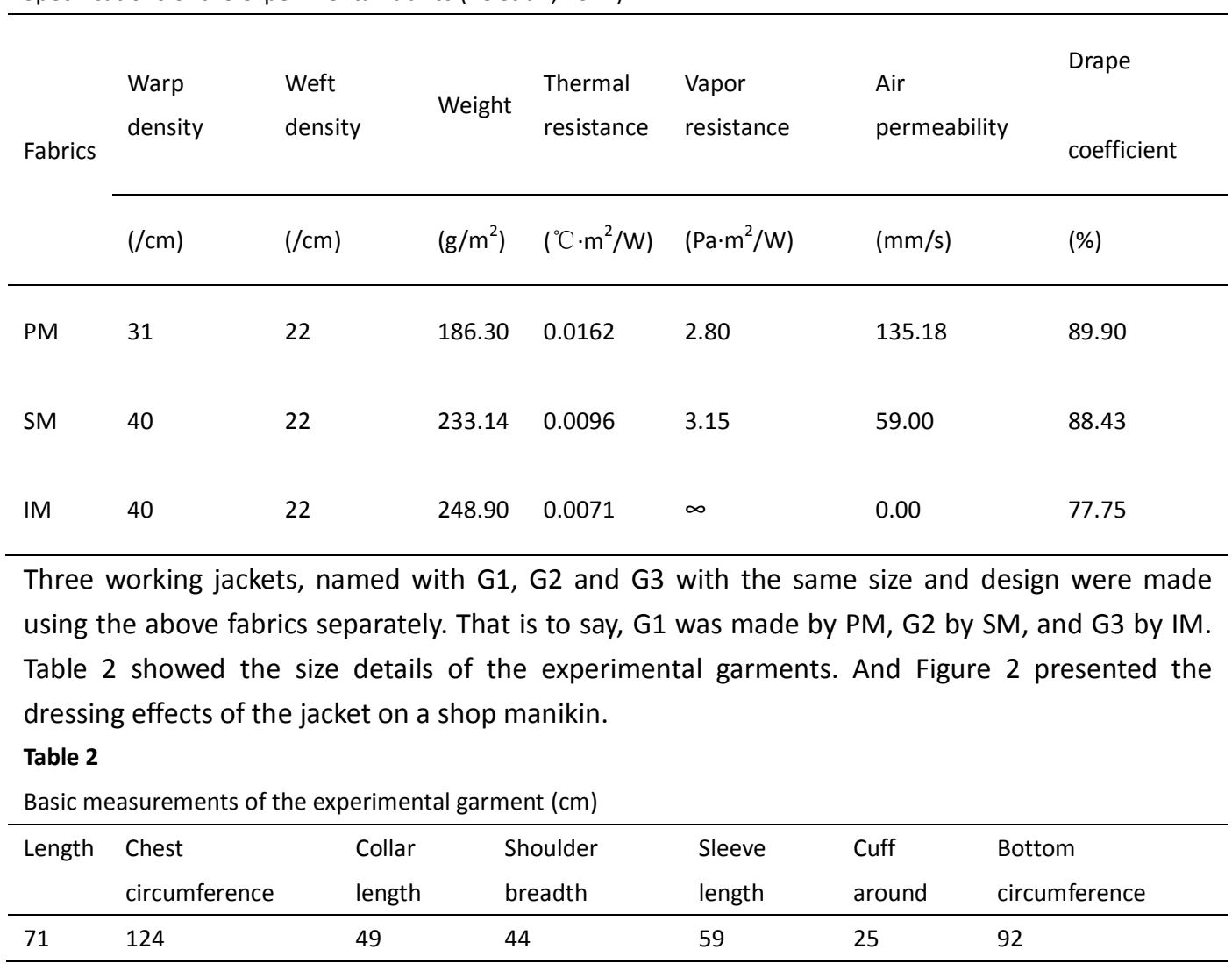




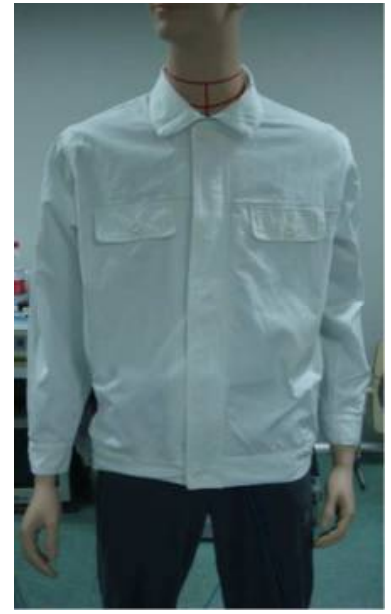

(a)

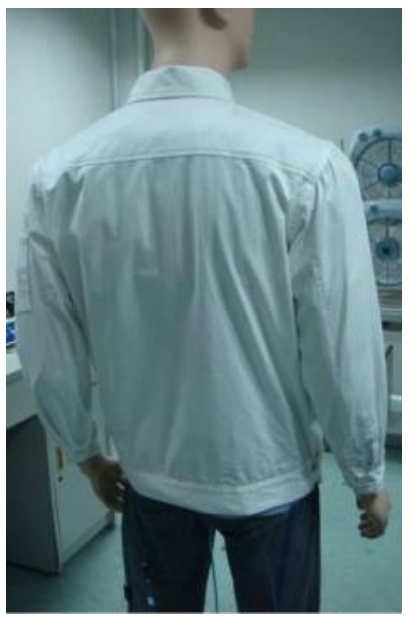

(b)

Figure 2. Dressing effects of the experimental garment on a shop manikin. (a) front side; (b) back side.

\subsection{Experimental protocol}

The experiment was carried out in an air conditioned chamber with $20 \pm 1^{\circ} \mathrm{C}$ room temperature, $50 \pm 5 \%$ relative humidity and $<0.3 \mathrm{~m} / \mathrm{s}$ air flow. On the upper body, all participants wore the same $100 \%$ cotton base shirt before the experimental jacket. On the lower body, the participants were offered the same sports pants but their own socks and shoes. For each participant, the testing was done at the same time of the day. The experimental jackets were put into the chamber 24 hours before the testing. And the experimental garments were worn randomly by the participants, who didn't know the differences before the experiments.

Each testing consisted of five phases:

1. Seated rest without wind;

2. Standing without wind;

3. Walking at $6 \mathrm{~km} / \mathrm{h}$ without wind;

4. Standing with the wind speed of $2 \mathrm{~m} / \mathrm{s}$;

5. Walking at $6 \mathrm{~km} / \mathrm{h}$ with the wind speed of $2 \mathrm{~m} / \mathrm{s}$.

Each phase lasted $10 \mathrm{~min}$.

Measurements during the testing included:

- LMV: the local ventilation of the experimental garments for each testing phase was measured using the system we developed (Ke et al., 2014; Ke et al., 2014). As the experimental jackets were bilaterally symmetrical, it can be assumed that the ventilation of the left arm equaled to the right arm's. Therefore only local ventilation of the chest, the back and the right arm were measured. Each testing repeated at least three times.

- Local skin temperature ( LST $_{\text {skin }}$ ): the local skin temperatures of the above three body parts were measured using the surface thermometers (Model 285-661, RS Component Ltd; accuracy \pm $0.1^{\circ} \mathrm{C}$ ) during the whole testing, 1 min intervals.

- Local microclimate temperature (LMT) and humidity (LMH): clothing local microclimate temperature and relative humidity were measured by platinum resistance thermometers (Model 362-9834, RS Component Ltd) and hygrothermometers (Model HIH 4000-001, RS Component Ltd), 1 min intervals.

- Heart rate $(\mathrm{HR})$ : the heart rate was monitored every 1 min by a polar heart rate monitor 
(SUUNTO, Finland).

- Clothing local surface temperature (LST surf $_{\text {) }}$ a non-contact infrared thermal imager (M7600, IMPAC Infrared Ltd, Germany) was adopted to measure the clothing local surface temperature just after one testing phase finished. And Micro spec 4.0 software was used to extract the average local surface temperature of the right arm, the chest and the back.

- Local and whole thermal sensation (TS), wetness sensation (WS), comfort sensation (CS): subjects were asked to declare their levels of thermal, wet and comfort perceptions every 10 min that is just when each phase was finished. Figure 3 showed the scales of the thermal, wetness and comfort sensation.

- The walking speed of the participants was controlled by a treadmill (832T, JOHNSON, China).

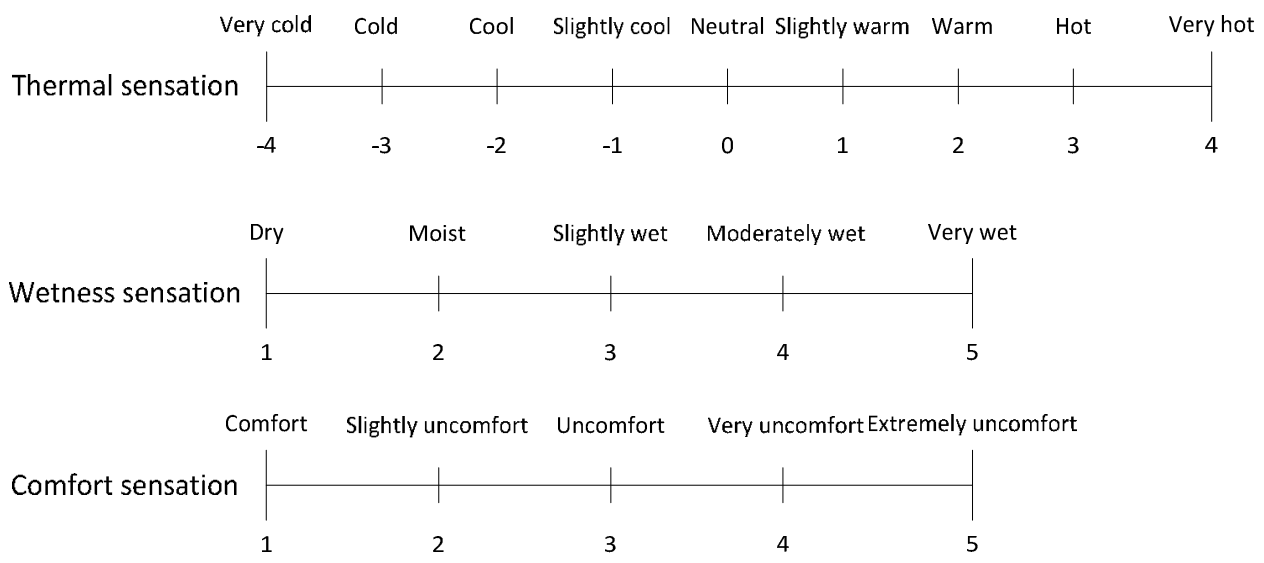

Figure 3. Sensory scales.(ISO10551, 1995)

\subsection{Data analysis}

The statistical software package SPSS 17.0 for Windows was adopted to do data analysis. Three-way ANOVA was used to identify the significant effects of three factors--fabric, garment region and exercise conditions on local ventilation and wear response. And post-hot tests were conducted to analyze the significant differences between the levels of the factors. For each factor, two-way ANOVA was adopted to analyze the significant effects of fabric and exercise conditions on the local ventilation. The linear regression analysis was conducted to identify the relationships between clothing local ventilation and wear response. The level of significance was set at 0.05 .

\section{Results and discussion}

\subsection{LMV}

As was shown in Figure 4, the local ventilation were related on fabric, garment region, exercise and their interactions. For fabric conditions, the three levels differed significantly from each other $(p<0.001)$ with the order G1 > G2 > G3. The three levels of factor "garment region" also differed significantly $(p<0.001)$. Overall, the ventilation of the back was highest, followed by the chest and the right arm. The results were different from those of Ueda et al's study (Ueda et al., 2006). The reason was that the back apertures of the experimental garments in this study were bigger than these in the previous research. For the exercise conditions, the average LMV from high to low were walking at $2 \mathrm{~m} / \mathrm{s}$, standing at $2 \mathrm{~m} / \mathrm{s}$, walking, standing, sitting $(\mathrm{p}<0.001)$. This result was 
consistent with Havenith's research on whole garment ventilation (Havenith et al., 1990).

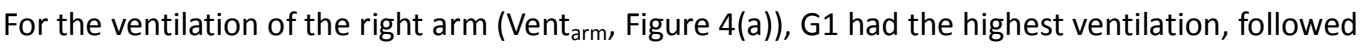
by $G 2, G 3(p<0.001)$. In addition, walking and wind increased Vent $t_{\text {arm }}$ obviously $(p<0.001)$. Among other conditions, Vent ${ }_{a r m}$ had its biggest values at walking with wind. But no significant difference was found between the Vent $t_{\text {arm }}$ at sitting and at standing $(p=0.341)$. It indicated that the effects of walking on the Vent $\mathrm{arm}_{\mathrm{m}}$ were more obvious than those of the wind.

Figure $4(\mathrm{~b})$ presented the chest ventilation (Vent chest $_{\text {) }}$ in different conditions. It was interesting that the Vent chest $_{\text {of }} \mathrm{G} 3$ at walking without wind was bigger than G2. The reason could be contributed on that the local ventilation was affected by the combination of walking and head-on wind (Lumley et al., 1991). Walking increased the air exchange of the chest part through garment apertures. But meanwhile the head-on wind decreased the chest microclimate volume and then may decrease the Vent $_{\text {chest }}$. Vent chest $_{\text {ct }}$ at walking and standing with wind increased $11.4 \%$ and $4.6 \%$ respectively compared with the average ventilation at standing. This illustrated that walking had more obvious effects on the Vent chest $_{\text {than }}$ those of the wind. And it was also consistent with the Vent $\mathrm{arm}_{\text {. }}$

For the back ventilation $\left(\right.$ Vent $_{\text {back, }}$ Figure 4(c)), the situations were different from those of the $V_{\text {Vent }}$ arm $_{\text {and }}$ Vent chest. $_{\text {. }} 1$ had the highest Vent $t_{\text {back }}$ except when standing with wind. For this

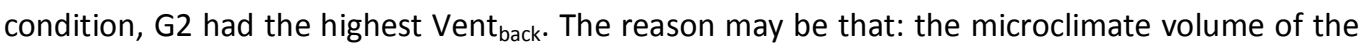
back increased when facing to the wind. As the fabric of G2 was stiffer than that of G1, this caused the bigger back microclimate volume of $\mathrm{G} 2$ at wind than that of G1. G3 had the smallest back ventilation except when walking at $2 \mathrm{~m} / \mathrm{s}$. This may be caused by the measuring error, as the absolute value of the standard deviation for $G 3$ at walking with $2 \mathrm{~m} / \mathrm{s}$ was bigger than the difference of the Vent back $_{\text {for }} \mathrm{G} 2$ and G3. Walking increased $20.4 \%$ Vent $_{\text {back }}$ on average compared with those of standing. Wind increased $52.5 \%$ Vent $_{\text {back }}$ on average. This illustrated that wind had more effects on the Vent back $_{\text {than }}$ walking. This also differed from Vent ${ }_{\text {arm }}$ and Vent $t_{\text {chest. }}$.

In summary, the local ventilation of chest and arm was proportional to fabric permeability. And the effects of walking (pumping effects) on chest and arm ventilation were more obvious than wind. But fabric stiffness property should also be considered carefully except for fabric permeability when designing garments with better back ventilation.

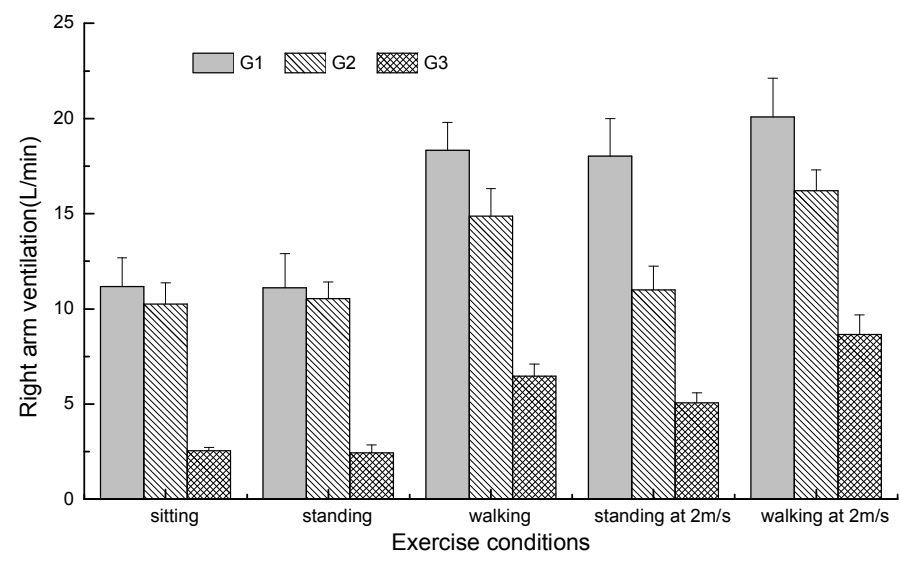

(a) 


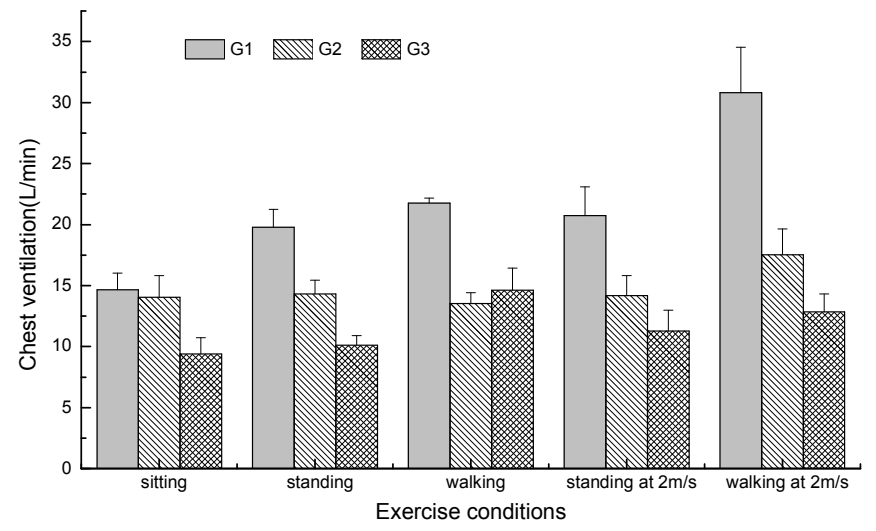

(b)

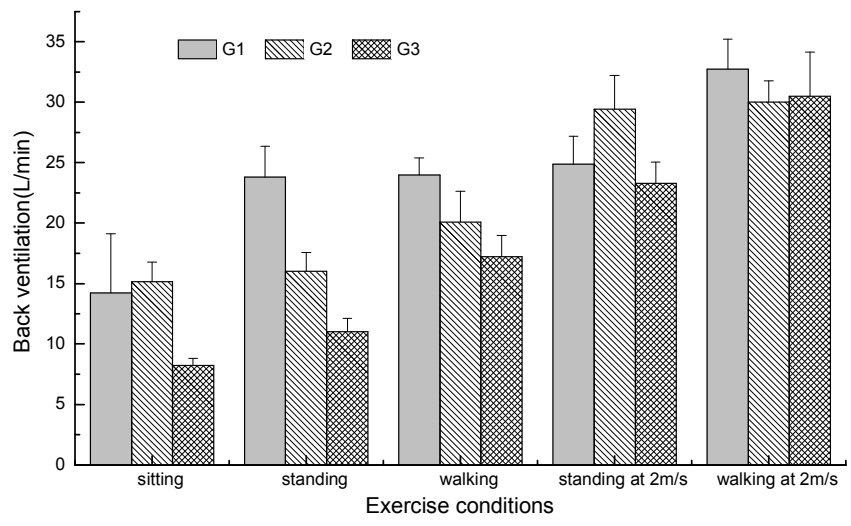

(c)

Figure 4. Local ventilation in different conditions. (a) right arm ventilation; (b) chest ventilation; (c) back ventilation.

\subsection{Wearer responses}

3.2.1 $L S T_{\text {surf }}$

Three-way ANOVA was adopted to analyze the effects of exercise, fabric and garment region on $\mathrm{LST}_{\text {surf }}$ (Figure 5). And then post-hoc tests were conducted to identify the significant differences between the $\mathrm{LST}_{\text {surf }}$ of the levels of the above factors. The results indicated that exercise and garment region affected the LST $_{\text {surf }}$ significantly $(p<0.001)$, with the order back $>$ chest $>$ right arm. The LST $_{\text {surf }}$ differed significantly $(p<0.05)$ at different exercise conditions except between sitting and standing $(p=0.813)$. But there were no significant differences of the $\mathrm{LST}_{\text {surf }}$ among the three fabrics $(p=0.649)$.

Figure 5(a) showed the average surface temperature of the right arm ( LST $_{\text {surf-arm }}$ ) in different fabric and exercise conditions. Exercise conditions but not fabric affected LST $_{\text {surf-arm. Wind }}$ decreased the $\mathrm{LST}_{\text {surf-arm }}$ obviously. There were no significant differences for $\mathrm{LST}_{\text {surf-arm }}$ at the condition without wind, such as sitting, standing and walking. Under the wind, LST $_{\text {surf-arm }}$ of the right arm decreased sharply even no walking. Although the LST was affected by both the exercise intensity and wind, it was obvious the effects of exercise intensity on LST $_{\text {surf }}$ were smaller than those of the wind in this study.

The local surface temperature of the chest (LST surf-chest $_{\text {) }}$ in different exercise conditions for the 
three experimental garments was presented in Figure 5(b). Both the exercise conditions and the fabric affected $\mathrm{LST}_{\text {surf-chest }}$ significantly $(\mathrm{p}<0.001, \mathrm{p}<0.05)$. Similar with the right arm, $\mathrm{LST}_{\text {surf-chest }}$ at standing with wind was smallest, followed by walking with wind. And the LST $_{\text {surf-chest }}$ showed higher at the exercise conditions without wind.

The LST $_{\text {surf-back }}$ (Local surface temperature of the back) in different conditions (Figure 5(c)) was

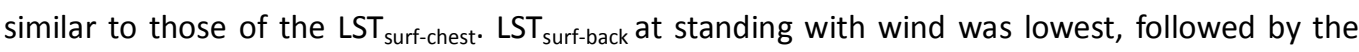
$\mathrm{LST}_{\text {surf-back }}$ at walking with wind. There were no significant differences between the $\mathrm{LST}_{\text {surf-back }}$ at sitting, standing and walking.

Overall, fabric permeability did not impact the LST $_{\text {surf }}$. Wind decreased LST $_{\text {surf }}$ significantly. And walking could not increase the $\mathrm{LST}_{\text {surf }}$ in this study.

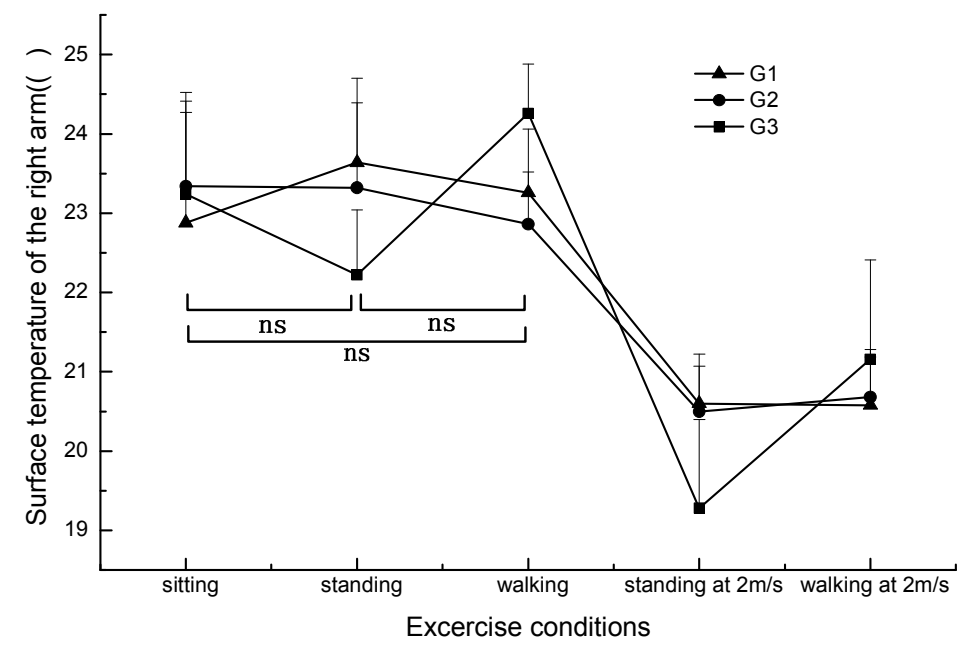

(a)

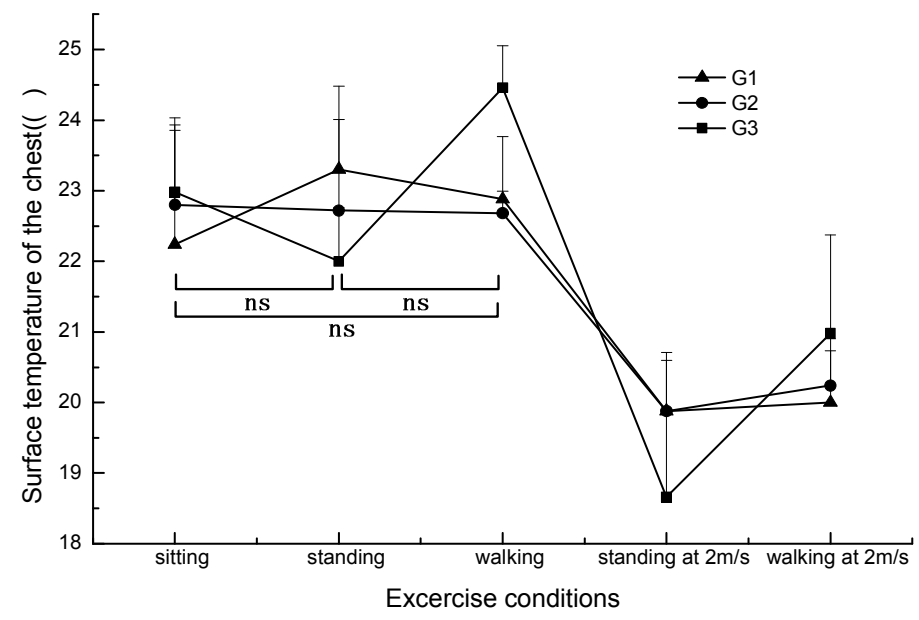

(b) 


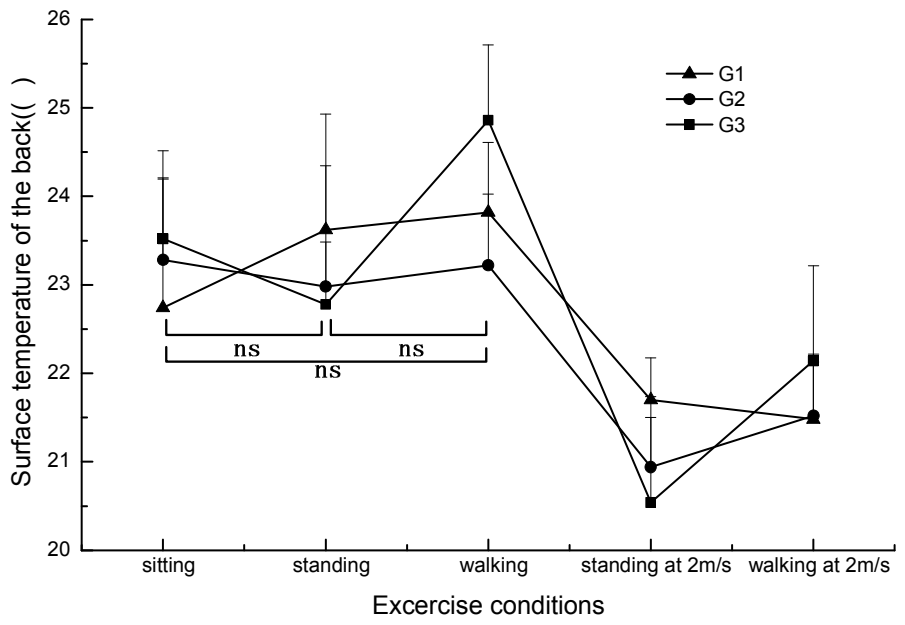

(c)

Figure 5. Local surface temperature in different conditions. (a) local surface temperature of the right arm; (b) local surface temperature of the chest; (c) local surface temperature of the back.

ns: none significance.

\subsection{2 $L S T_{\text {skin, }} L M T$ and $L M H$}

$\mathrm{LST}_{\text {skin }} \mathrm{S}$ of different garments, regions and exercise conditions were illustrated in Table 3 . There were no significant differences between the $L_{S T} T_{\text {skin }} S$ in different conditions $(p>0.05)$. But it was obvious that the right arm always had the smallest $\mathrm{LST}_{\text {skin }}$.

The average LMTs in different conditions were shown in Table 3. No significant differences between the LMTs were found ( $p>0.05)$. But overall the LMTs of the right arm were lower than those of the chest and the back. Meanwhile, the arm part of G3 had the highest LMT. The chest LMT of G3 was highest when there was no wind. But in wind conditions, the chest LMT of G1 was biggest. The reason may be that when there was wind, the chest part of the garment contacted directly with the human body.

\section{Table 3}

The local skin temperature and microclimate temperature of the right arm, chest and back (mean $\left.(\mathrm{SD}),{ }^{\circ} \mathrm{C}\right)$

\begin{tabular}{|c|c|c|c|c|c|c|c|}
\hline \multirow{2}{*}{ Garment } & \multirow{2}{*}{ Exercise conditions } & \multicolumn{3}{|l|}{$\mathrm{LST}_{\text {skin }}$} & \multicolumn{3}{|l|}{ LMT } \\
\hline & & Right arm & Chest & Back & Right arm & Chest & Back \\
\hline \multirow[t]{5}{*}{ G1 } & sitting & $32.02(0.08)$ & $33.21(0.23)$ & $32.91(0.27)$ & $25.21(0.53)$ & $28.10(0.58)$ & $27.81(0.84)$ \\
\hline & standing & $32.21(0.07)$ & $33.56(0.06)$ & $33.44(0.07)$ & $26.42(0.18)$ & $29.23(0.21)$ & $28.74(0.14)$ \\
\hline & walking & $32.15(0.09)$ & $33.60(0.05)$ & $33.52(0.13)$ & $25.70(0.22)$ & $29.23(0.20)$ & $28.80(0.38)$ \\
\hline & standing at $2 \mathrm{~m} / \mathrm{s}$ & $31.92(0.11)$ & $33.17(0.14)$ & $33.55(0.07)$ & $24.45(0.30)$ & $28.41(0.21)$ & $28.34(0.49)$ \\
\hline & walking at $2 \mathrm{~m} / \mathrm{s}$ & $31.69(0.09)$ & $33.23(0.22)$ & $33.52(0.33)$ & $24.10(0.16)$ & $28.55(1.01)$ & $27.72(0.44)$ \\
\hline \multirow[t]{5}{*}{ G2 } & sitting & $31.23(0.09)$ & $33.27(0.17)$ & $32.93(0.26)$ & $25.75(0.51)$ & $27.69(0.69)$ & $28.52(0.66)$ \\
\hline & standing & $30.97(1.17)$ & $33.60(0.05)$ & $33.35(0.09)$ & $26.20(0.14)$ & $28.16(0.33)$ & $28.91(0.20)$ \\
\hline & walking & $31.40(0.13)$ & $33.60(0.10)$ & $33.45(0.19)$ & $25.80(0.38)$ & $26.83(0.31)$ & $28.97(0.43)$ \\
\hline & standing at $2 \mathrm{~m} / \mathrm{s}$ & $31.14(0.22)$ & $33.13(0.14)$ & $33.09(0.11)$ & $24.53(0.20)$ & $25.52(0.22)$ & $27.99(0.41)$ \\
\hline & walking at $2 \mathrm{~m} / \mathrm{s}$ & $30.74(0.54)$ & $32.92(0.48)$ & $32.56(1.01)$ & $25.23(1.51)$ & $25.38(1.27)$ & $28.13(0.34)$ \\
\hline
\end{tabular}

(C) Emerald Group Publishing Limited

This is a pre-print of a paper and is subject to change before publication. This pre-print is made available with the understanding that it will not be reproduced or stored in a retrieval system without the permission of Emerald Group Publishing Limited. 


\begin{tabular}{llllllll}
\hline G3 & sitting & $31.03(0.12)$ & $32.98(0.21)$ & $32.72(0.29)$ & $24.87(0.61)$ & $29.11(0.54)$ & $27.37(0.67)$ \\
& standing & $31.33(0.02)$ & $33.40(0.06)$ & $33.04(0.03)$ & $25.15(0.16)$ & $29.39(0.29)$ & $28.46(0.14)$ \\
walking & $31.24(0.15)$ & $33.44(0.12)$ & $33.21(0.16)$ & $25.07(0.45)$ & $29.22(0.33)$ & $28.34(0.50)$ \\
standing at 2m/s & $31.09(0.13)$ & $33.05(0.19)$ & $33.04(0.21)$ & $23.06(0.50)$ & $27.94(0.71)$ & $28.07(0.78)$ \\
walking at 2m/s & $30.66(0.08)$ & $33.08(0.29)$ & $32.94(0.21)$ & $23.37(0.54)$ & $26.87(0.97)$ & $27.20(0.47)$ \\
\hline
\end{tabular}

The LMH in different conditions was given in Figure 6. Three-way ANOVA was conducted to analyze the significant effects of fabric, garment region and exercise conditions on the $\mathrm{LMH}$. The results showed that all the above three factors and the interactions among them affected the LMH significantly $(p<0.001)$. Post-hoc tests were then conducted to identify the differences in the levels of the factors, showing that the LMH differed significantly between all the levels of the three factors $(p<0.05)$.

For the microclimate humidity of the right arm $\left(\mathrm{LMH}_{\text {arm }}\right.$, Figure 6(a)), the $\mathrm{LMH}_{\text {arm }}$ was significantly affected by fabric and exercise conditions $(p<0.001, p<0.05)$. G3 had the highest $\mathrm{LMH}_{\text {arm }}$. The reason was that the fabric of G3 was impermeable. It would block the humidity evaporation under the microclimate. There were no significant differences between the $\mathrm{LMH}_{\mathrm{arm}} \mathrm{S}$ of $\mathrm{G} 1$ and G2. For exercise conditions, the $\mathrm{LMH}_{\text {arm }}$ were significantly different except between the $\mathrm{LMH}_{\mathrm{arm}} \mathrm{s}$ at sitting and standing with wind, walking and standing with wind. This may be correlated with the exercise order. (Ha et al., 1996).

As shown in Figure 6(b), fabric and exercise conditions also affected the $\mathrm{LMH}_{\text {chest }}$ significantly $(p<0.001, p<0.001)$. The three levels of garment also differed from each other $(p<0.05)$. Overall, the $\mathrm{LMH}_{\text {chest }}$ was correlated with fabric permeability. $\mathrm{G} 3$ had the highest $\mathrm{LMH}_{\text {chest }}$, followed by G2, G1. For the exercise conditions, there were also significant differences in the $\mathrm{LMH}_{\text {chest }}$ except between sitting and walking at $2 \mathrm{~m} / \mathrm{s}$, standing and walking ( $\mathrm{p}=0.667, \mathrm{p}=0.558) . \mathrm{LMH}_{\text {chest }}$ at walking or standing were lowest. $\mathrm{LMH}_{\text {chest }}$ at sitting and walking with wind were highest. This indicated that $\mathrm{LMH}_{\text {chest }}$ was impacted by the combined effects of posture, exercise, and wind.

For the microclimate humidity of the back $\left(\mathrm{LMH}_{\text {back}}\right.$, Figure 6 (c)), fabric and exercise conditions also affected the $\mathrm{LMH}_{\text {back }}$ significantly $(\mathrm{p}<0.001, \mathrm{p}<0.001)$. Post-hoc tests indicated that the three levels of fabric differed from each other. Similar with $\mathrm{LMH}_{\text {chest }}$, the $\mathrm{LMH}_{\text {back }} \mathrm{S}$ of $\mathrm{G} 3$ were also larger than $\mathrm{G} 2$ and $\mathrm{G} 1$. For the exercise conditions, the $\mathrm{LMH}_{\text {back }}$ from high to low were walking at $2 \mathrm{~m} / \mathrm{s}$, walking, sitting, sitting at $2 \mathrm{~m} / \mathrm{s}$, standing. On the whole, $\mathrm{LMH}$ was negative correlation to fabric permeability for chest and back region. 


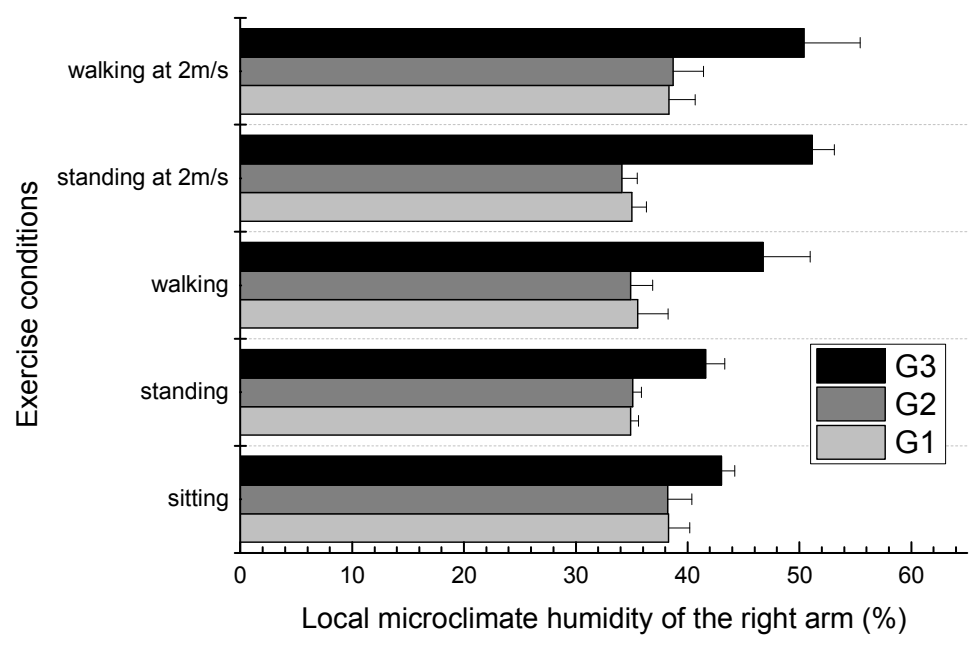

(a)

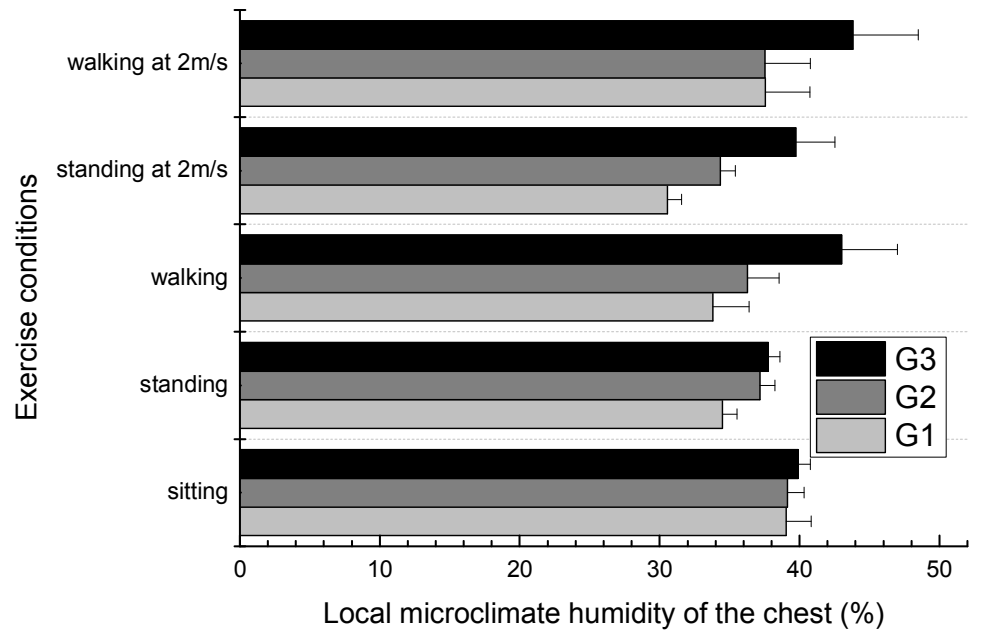

(b)

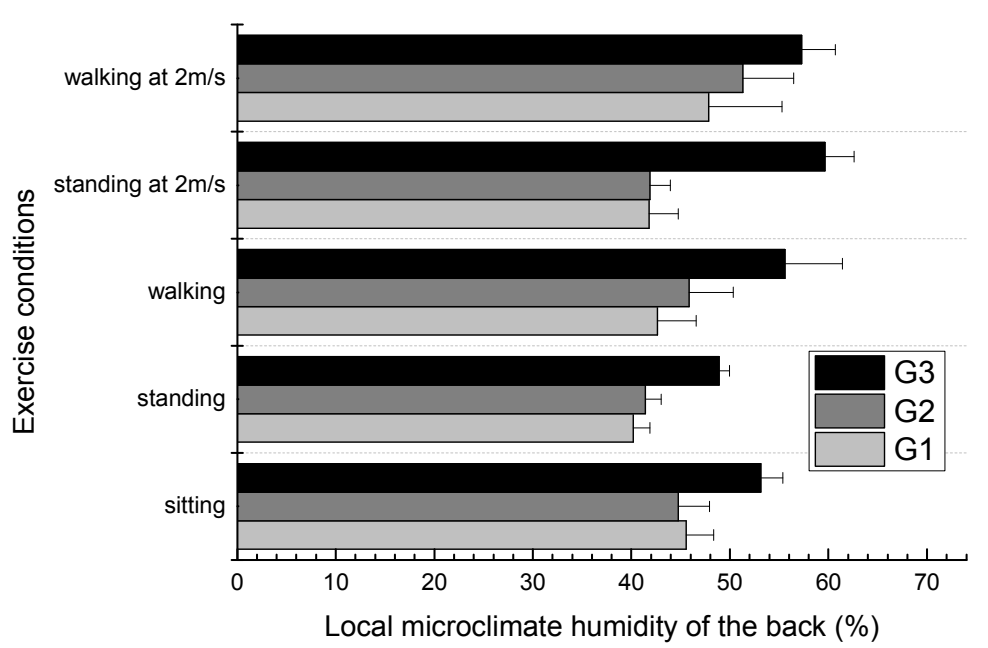

(c)

Figure 6. Local microclimate humidity in different conditions. (a) local microclimate humidity of the right arm; (b)

(C) Emerald Group Publishing Limited

This is a pre-print of a paper and is subject to change before publication. This pre-print is made available with the understanding that it will not be reproduced or stored in a retrieval system without the permission of Emerald Group Publishing Limited. 


\subsubsection{HR}

Figure 7 showed the average HR of the subject in different garment and exercise conditions. Two-way ANOVA analysis indicated that both fabric and exercise conditions affected the HR significantly $(p<0.001, p<0.001)$. And results of post-hoc tests showed that the HRs were lowest when wearing $G 1$ but no significant differences between $G 2$ and $G 3(p=0.871)$. While for exercise conditions, the HRs differed significantly except between walking and walking with wind. This illustrated that wind didn't affect HR when walking. HR was highest at walking, followed by standing at $2 \mathrm{~m} / \mathrm{s}$, standing and sitting.

One-way ANOVA was then conducted to analyze the significant effects of fabric in static conditions (sitting, standing and standing at $2 \mathrm{~m} / \mathrm{s}$ ). The results indicated that at sitting or walking without wind, HRs of G1 was lowest. But the HRs of G2 and G3 didn't show significant difference $(p=0.113)$. At walking with wind, the results showed difference from the above two conditions. G3 had the highest HR, followed by $G 2$ and G1. This indicated that the HR was proportional to fabric permeability at walking with wind.

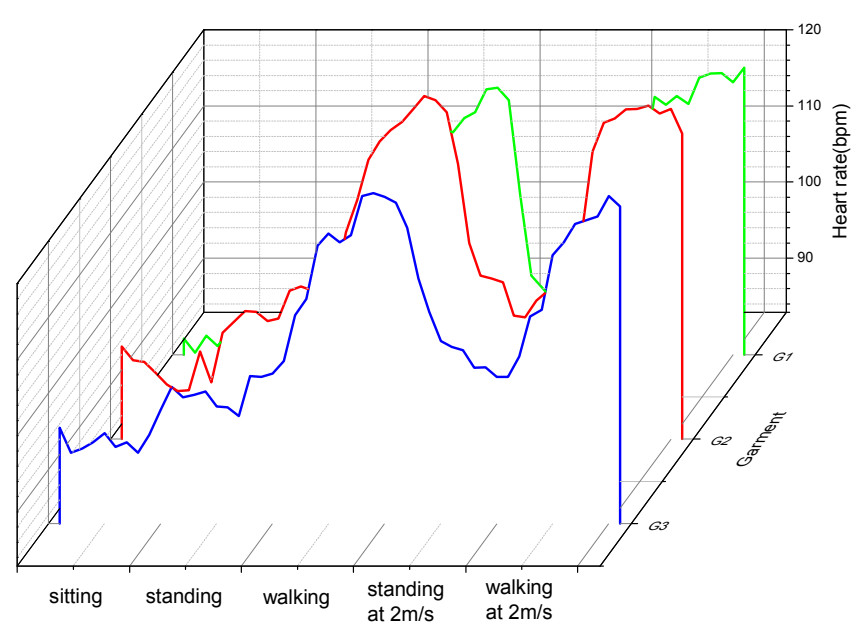

Figure 7. Average heart rate in different exercise conditions

\subsubsection{Subjective perceptions}

Figure 8 presented the average whole and local subjective evaluations of the experimental garments in different exercise conditions.

For the thermal sensation (TS, Figure $8(\mathrm{a})$ ), it was obvious that the ratings were highest when walking without wind. But when walking at wind, the TS rating decreased $27.4 \%$ on average. It was interesting that there were no significant differences among the average TS of sitting, standing and standing with wind ( $p>0.05)$.

For the wetness sensation (WS, Figure $8(\mathrm{~b})$ ), the average rating was also highest when walking. And wind decreased the wetness ratings by $14.7 \%$ on average. All the WS values of different fabric rated the same at sitting. And the sensations also rated the same at standing except when wearing G2. When standing at $2 \mathrm{~m} / \mathrm{s}$, the sensations also rated the same except G3-Back. But the differences between the WS of G3-Back and others were not significant $(p>0.05)$. It was 
suggested to ask both the local and whole WSs in exercise conditions. But there was no need to do this in still conditions.

For the comfort sensation (CS, Figure 8(c)), the whole and local CS ratings of different fabrics have the same values at sitting, walking and walking with wind, separately. But the CS ratings of G3 decreased at standing with or without wind. This means that the subjects felt relatively uncomfortable when wearing $\mathrm{G} 3$ under these conditions. The situations may be correlated with the changes of the ventilation. The ventilation of G3 was small when standing. But the air exchange through garment apertures increased when walking. And this may directly increase the CS ratings. This guess will be further identified by discussing the relationship between the ventilation and the $\mathrm{CS}$ rating.

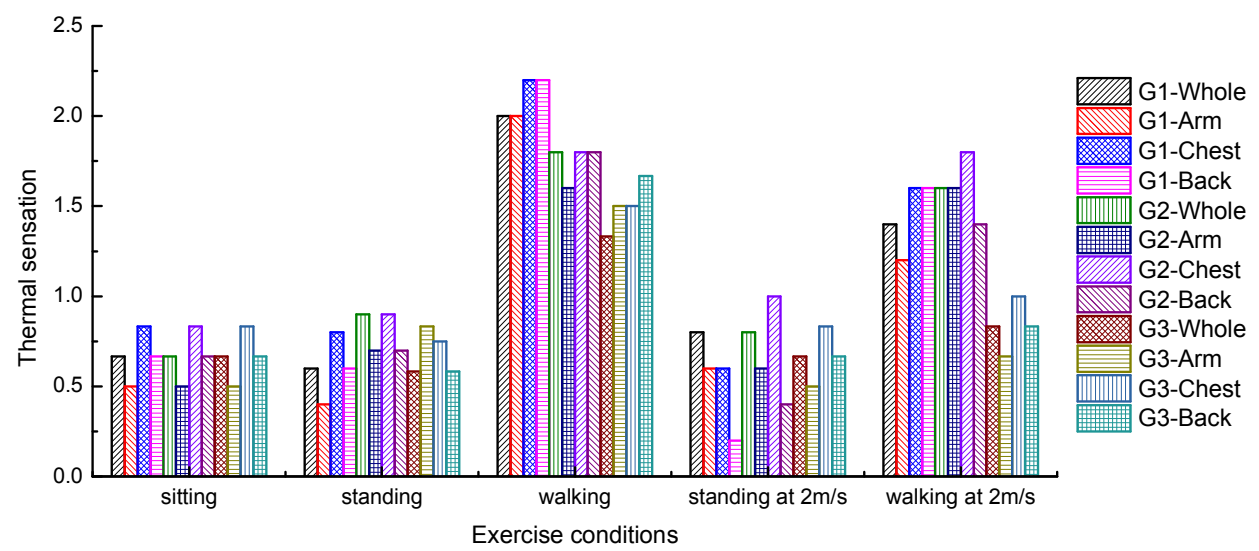

(a)

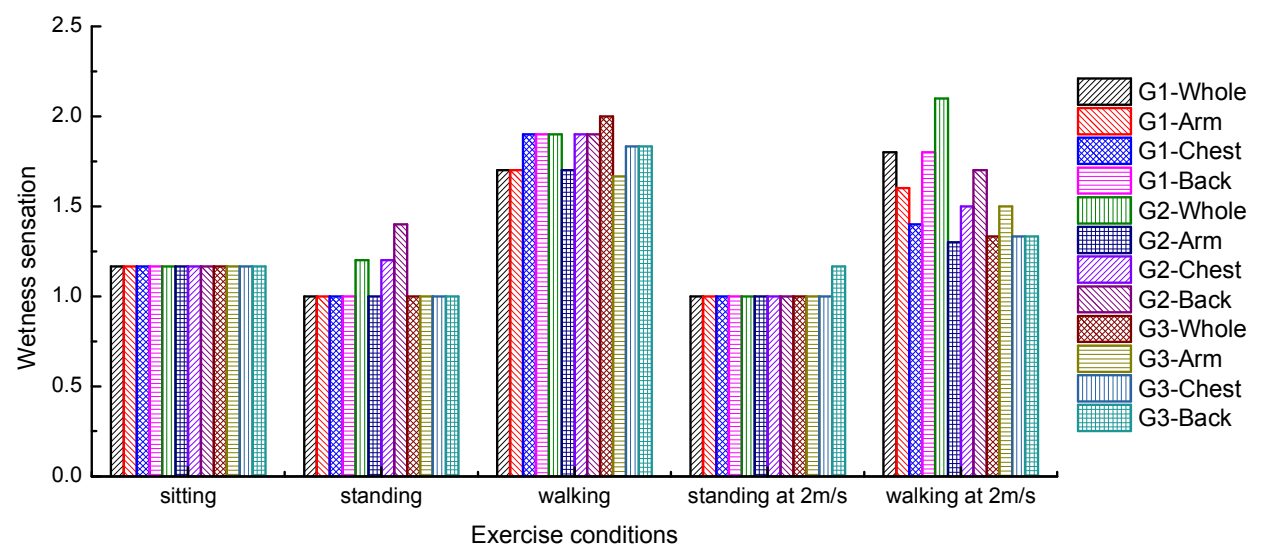

(b) 


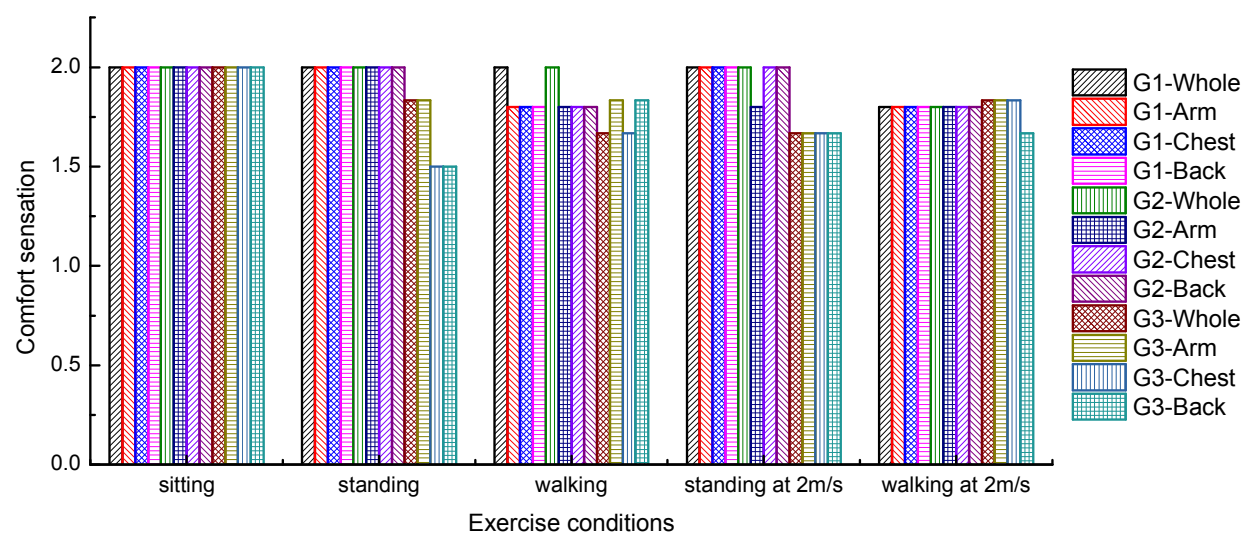

(c)

Figure 8. Subjective ratings of the experimental garments in different conditions. (a) thermal sensation; (b) wetness sensation; (c) comfort sensation.

For the eardrum temperature (ET), there were no significantly differences of the ETs between all the garment and exercise conditions ( $p>0.05)$. The range of the ETs was from $36.0^{\circ} \mathrm{C}$ to $36.6^{\circ} \mathrm{C}$.

\subsection{Relationship between the LMV and wearer responses}

\subsubsection{Relationship between the LMV and the $L M H$}

For the right arm and the chest, there were no significant linear correlations between LMV and the related $L_{S F}$ surf $(p=0.485, p=0.493)$. But $L M_{\text {back }}$ was linearly correlated with $L T_{\text {surf-back, as was }}$ shown in Figure 9 (a) $(p=0.025, R=0.574)$. And it was an inverse relationship.

\subsubsection{Relationship between the $L M V$ and the $L M H$}

As discussed in chapter 3.2.2, there were no significant correlations between LMV and LST $_{\text {skin }}$ or LMT.

As shown in Figure 9(b), $\mathrm{LMV}_{\text {arm }}$ had significant inversely linear relationship with $\mathrm{LMH}_{\mathrm{arm}}(\mathrm{p}=0.018$, $\mathrm{R}=0.600$ ).

For the chest, the LMV and LMH had no significant correlation $(p=0.105)$. But if the data of walking with wind conditions for G1 removed, they showed significant linear relationship $(p=0.012)$, as was presented in Figure 9(c).

\subsubsection{Relationship between the LMV and the HR}

There were no significant linear relationship between $H R$ and $L M V_{\text {arm }}$ or $\operatorname{LMV}_{\text {chest }}(p=0.418$, $p=0.608)$. But it was interesting that $L_{M V}$ back showed significant linear correlation with the $H R$ $(\mathrm{p}=0.048, \mathrm{R}=0.456)$.

\subsubsection{Relationship between the LMV and subjective evaluations}

There was no significant linear relationship between LMV and WS or CS. But the situations were different for the TS.

For the right arm, there was no significant correlation between LMV and TS ( $p=0.071)$. But if the values of $\mathrm{G} 3$ removed, the significant linear relationship between $L M V_{\text {arm }}$ and $T_{\text {arm }}$ could be set up $(p=0.036)$, as was shown in Figure 9(e).

For the chest, there was no significant correlation between LMV and TS either $(p=0.119)$. But if the values of $\mathrm{G} 1$ removed, $\mathrm{LMV}_{\text {chest }}$ significantly correlated with $\mathrm{TS}_{\text {chest }}(p=0.036)$, as was illustrated in Figure 9(f).

In addition, $\mathrm{LMV}_{\text {back }}$ didn't have significant linear relationship with $\mathrm{TS}_{\text {back }}(\mathrm{p}=0.439)$. 


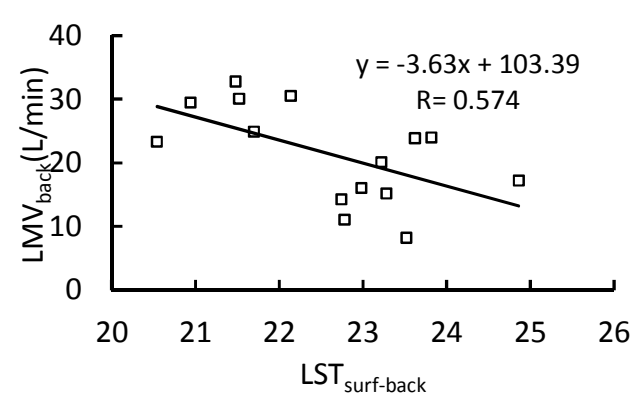

(a)

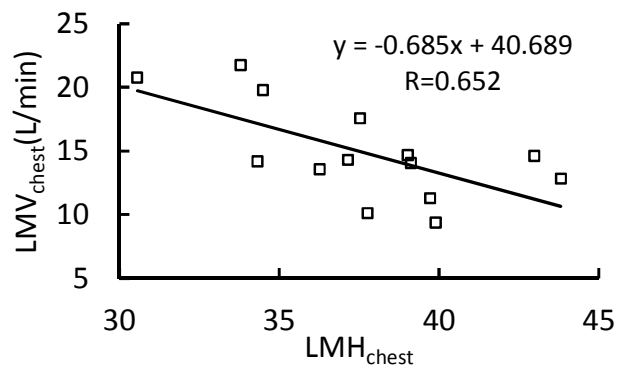

(c)

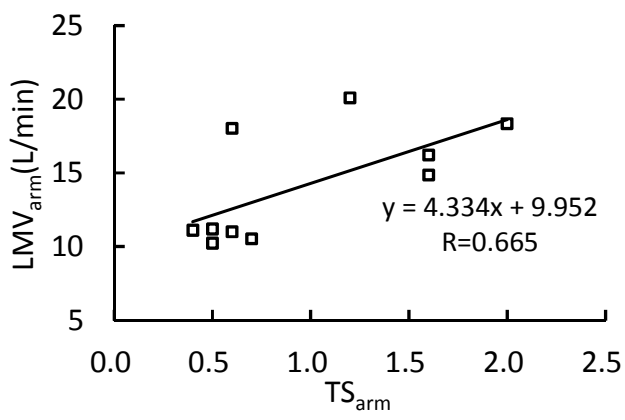

(e)

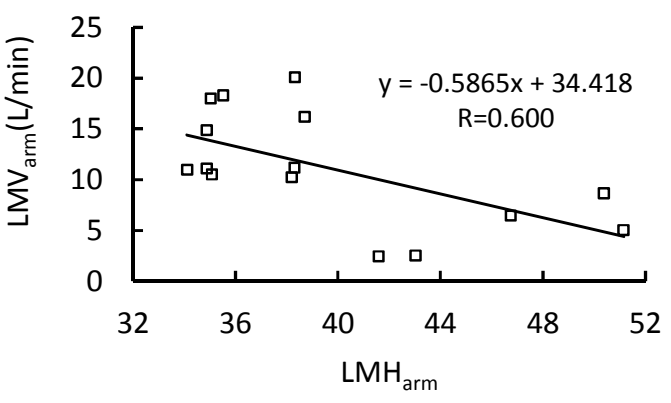

(b)

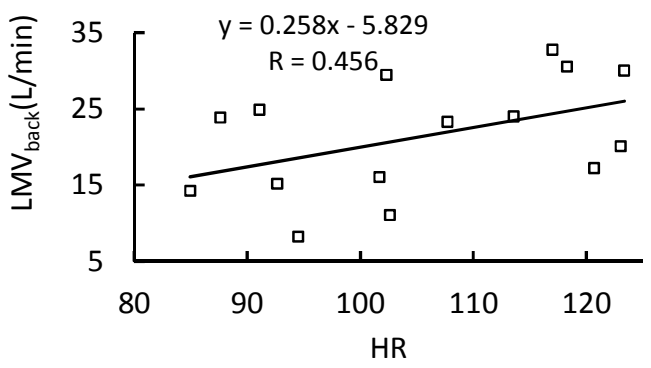

(d)

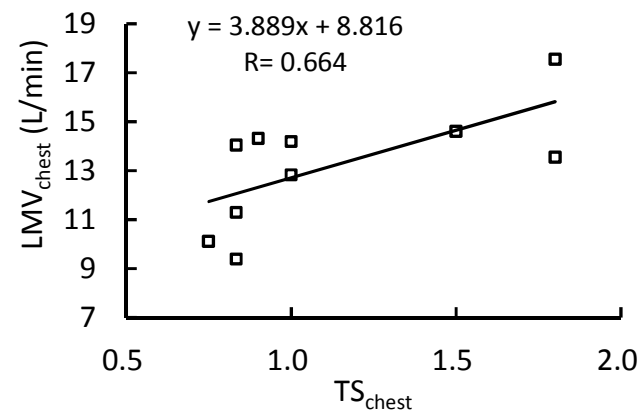

(f)

Figure 9. Relationship between the local ventilation and wear response. (a) Relationship between the $L M V_{\text {back }}$ and the $\mathrm{LSF}_{\text {back; }}$ (b) Relationship between the $\mathrm{LMV}_{\text {arm }}$ and the $\mathrm{LMH}_{\text {arm }}$; (c) Relationship between the LMV chest and the $\mathrm{LMH}_{\text {chest }}$ ( $\mathrm{d}$ ) Relationship between the $\mathrm{LMV}_{\text {back }}$ and the HR; (e) Relationship between the $\mathrm{LMV}_{\text {arm }}$ and the TS arm; $(\mathrm{f}$ ) Relationship between the $\mathrm{LMV}_{\text {chest }}$ and the $\mathrm{TS}_{\text {chest }}$.

\section{Conclusions}

Clothing local ventilation and wear responses of three working jackets in different exercise conditions were studied. And the relationships of them were explored. A local ventilation measuring system was developed based on the $\mathrm{LH}^{\prime} \mathrm{S}$ method. The results showed that the local ventilation of the three garment regions presented different variations. The local ventilation of chest and arm was proportional to fabric permeability. And the effects of walking (pumping effects) on chest and arm ventilation were more obvious than wind. But fabric stiffness property should also be considered carefully except for fabric permeability when designing garments with better back ventilation. In addition, fabric permeability did not impact the local surface temperature. And wind but not walking could affect local surface temperature in this study. Moreover, there were no significant differences of the local skin temperature and microclimate 
temperature between the experimental garments in different exercise conditions. Local microclimate humidity was negative correlation to fabric permeability for chest and back region. Besides, the clothing local ventilation had significant linear relationship with local surface temperature (at back), local microclimate humidity (at arm and chest), heart rate (at back) and thermal sensation (at arm and chest). This may give some suggestions on local ventilation prediction. Overall, the research can give some suggestions or guidelines for garment design and selection of the suitable garments for workers.

\section{References}

Bogerd, C. P., Brühwiler, P. A., Rossi, R. M, Heat loss and moisture retention variations of boot membranes and sock fabrics: A foot manikin study. (2012), International Journal of Industrial Ergonomics, Vol. 42, pp. 212-218.

Bouskill, L., Havenith G., Kuklane K., Parsons K. C., Withey W. R., Relationship between clothing ventilation and thermal insulation. (2002), American Industrial Hygiene Association, Vol. 63, pp. 262-268.

Birnbaum, R. R., Crockford, G. W., Measurement of the clothing ventilation index. (1978), Applied Ergonomics, Vol. 9, pp. 194-200.

Ha, M., Tokura H., Tanaka Y., Holmér I, Effects of two kinds of underwear on thermophysiological responses and clothing microclimate during $30 \mathrm{~min}$ walking and $60 \mathrm{~min}$ recovery in the cold. (1996), Applied Human Science, Vol. 15, pp. 33-39.

Havenith, G., Heus, R., Lotens, W. A, Clothing ventilation, vapour resistance and permeability index: changes due to posture, movement and wind. (1990), Ergonomics, Vol. 33, pp. 989-1005.

Havenith, G., Zhang, P., Hatcher, K., Daanen, H., Comparison of two tracer gas dilution methods for the determination of clothing ventilation and of vapour resistance. (2010), Ergonomics, Vol. 53, pp. 548-558.

Holland, E. J, Wilson, C. A., Laing, B. E. Niven., Microclimate ventilation of infant bedding. (1999), International Journal of Clothing Science and Technology, Vol. 11, pp. 226-239.

ISO 10551, Ergonomics of the thermal environment-assessment of the influence of the thermal environment using subjective judgement scales. (1995), Geneva.

Ke, Y., Havenith, G., Li, J., Li, X. H., A New Experimental Study of Influence of Fabric Permeability, Clothing Sizes, Openings and Wind on Regional Ventilation Rates. (2013), Fibers and Polymers, Vol. 14, pp. 1906-1911.

Ke, Y., Havenith, G., Zhang, X. H., Li, X. H., Li, J., Effects of wind and clothing apertures on local clothing ventilation rates and thermal insulation. (2014), Textile Research Journal, Vol. 84, pp. 941-952.

Ke, Y., Li, J., Havenith, G, An improved experimental method for local clothing ventilation measurement. (2014), International Journal of Industrial Ergonomics, Vol. 44, pp. 75-81.

Lotens, W. A., Havenith, G., Ventilation of rainwear determined by a trace gas method. (1988), Environmental Ergonomics, Vol. 34, pp. 162-175.

Lumley, S. H., Story, D. L., Thomas, N. T, Clothing ventilation - update and applications. (1991), Applied Ergonomics, Vol. 22, pp. 390-394.

Satsumoto, Y., Havenith, G, Evaluation of overall and local ventilation in diapers. (2010), Textile Research Journal, Vol. 80, pp. 1859-1871.

Satsumoto, Y., Takeuchi, M., Habu, C., Yoshizaki, A., Development of device to evaluate the ventilation of diaper. (2008), Proceedings of Korea-Japan Joint Symposium on Human-Environment Syetem, Cheju, 
Korea .

Satsumoto, Y., Takeuchi, M., Havenith, G, The effect of size factor of leather shoes on ventilation rate in shoes. (2011), The Fourth International Conference on Human-Environment System (ICHES 2011), Yokoyama, S. Sapporo, Japan,pp. 499-504.

Ueda, H., Inoue, Y., Matsudaira, M., Araki, T., Regional microclimate humidity of clothing during light work as a result of the interaction between local sweat production and ventilation. (2006), International Journal of Clothing Science and Technology, Vol. 18, pp. 225-234. 